\title{
Research and trends in STEM education: a systematic analysis of publicly funded projects
}

\author{
Yeping $\mathrm{Li}^{1^{*}}$, Ke Wang ${ }^{2}$, Yu Xiao ${ }^{1}$, Jeffrey E. Froyd ${ }^{3}$ and Sandra B. Nite ${ }^{1}$
}

\begin{abstract}
Taking publicly funded projects in STEM education as a special lens, we aimed to learn about research and trends in STEM education. We identified a total of 127 projects funded by the Institute of Education Sciences (IES) of the US Department of Education from 2003 to 2019. Both the number of funded projects in STEM education and their funding amounts were high, although there were considerable fluctuations over the years. The number of projects with multiple principal investigators increased over time. The project duration was typically in the range of 3-4 years, and the goals of these projects were mostly categorized as "development and innovation" or "efficacy and replication." The majority of the 127 projects focused on individual STEM disciplines, especially mathematics. The findings, based on IES-funded projects, provided a glimpse of the research input and trends in STEM education in the USA, with possible implications for developing STEM education research in other education systems around the world.
\end{abstract}

Keywords: Review, Scholarship, Status, STEM education research, STEM funding, Trends

\section{Introduction}

The rapid development of science, technology, engineering, and mathematics (STEM) education and research since the beginning of this century has benefited from strong, ongoing support from many different entities, including government agencies, professional organizations, industries, and education institutions (Li, 2014). Typically, studies that summarized the status of research in STEM education have used publications as the unit of their analyses (e.g., Li et al., 2019; Li et al., 2020; Margot \& Kettler, 2019; Minichiello et al., 2018; Otten, Van den Heuvel-Panhuizen, \& Veldhuis, 2019; Schreffler et al., 2019). Another approach, which has been used less frequently, is to study research funding. Although not all research publications were generated from funded projects and not all funded projects have been equally productive, as measured by publications, research funding and publications present two different, but related perspectives on the state of research in STEM education. Our review focuses on research funding.

\section{Types of funding support to education research}

There are different types of sources and mechanisms in place to allocate, administer, distribute, and manage funding support to education. In general, there are two sources of funding: public and private.

Public funding sources are commonly government agencies that support education program development and training, project evaluation, and research. For example, multiple state and federal agencies in the

\footnotetext{
* Correspondence: yepingli@tamu.edu

${ }^{1}$ Texas A\&M University, College Station, TX 77843-4232, USA

Full list of author information is available at the end of the article
}

\section{Springer Open}

(c) The Author(s). 2020 Open Access This article is licensed under a Creative Commons Attribution 4.0 International License, which permits use, sharing, adaptation, distribution and reproduction in any medium or format, as long as you give appropriate credit to the original author(s) and the source, provide a link to the Creative Commons licence, and indicate if changes were made. The images or other third party material in this article are included in the article's Creative Commons licence, unless indicated otherwise in a credit line to the material. If material is not included in the article's Creative Commons licence and your intended use is not permitted by statutory regulation or exceeds the permitted use, you will need to obtain permission directly from the copyright holder. To view a copy of this licence, visit http://creativecommons.org/licenses/by/4.0/. 
USA provide and manage funding support to education research, programs and training, including the US Department of Education (ED), the National Science Foundation (NSF), and the National Endowment for the Humanities-Division of Education Programs. Researchers seeking support from public funding sources often submit proposals that are vetted through a well-structured peer-review process. The process is competitive, and the decision to fund a project validates both its importance and alignment with the funding agency's development agenda. Changes in the agencies' agendas and funding priorities can reflect governmental intentions and priorities for education and research.

Private funding sources have played a very important role in supporting education programs and research with a long history. Some private funding sources in the USA can be sizeable, such as the Bill \& Melinda Gates Foundation (https://www.gatesfoundation.org), while many also have specific foci, such as the Howard Hughes Medical Institute (https:// www.hhmi.org) that is dedicated to advancing science through research and science education. At the same time, private funding sources often have their own development agendas, flexibility in deciding funding priorities, and specific mechanisms in making funding decisions, including how funds can be used, distributed, and managed. Indeed, private funding sources differ from public funding sources in many ways. Given many special features associated with private funding sources, including the lack of transparency, we chose to examine projects that were supported by public funding sources in this review.

\section{Approaches to examining public research funding support}

One approach to studying public research funding support to STEM education would be to examine requestsfor-proposals (RFPs) issued by different government agencies. However, those RFPs tend to provide guidelines, which are not sufficiently concrete to learn about specific research that is funded. In contrast, reviewing those projects selected for funding can provide more detailed information on research activity. Figure 1 shows a flowchart of research activity and distinguishes how funded projects and publications might provide different perspectives on research. In this review, we focus on the bolded portion of the flowchart, i.e., projects funded to promote STEM education.

\section{Current review}

Why focus on research funding in the USA?

Recent reviews of journal publications in STEM education have consistently revealed that scholars in the USA played a leading role in producing and promoting scholarship in STEM education, with about $75 \%$ of authorship credits for all publications in STEM education either in the International Journal of STEM Education alone from 2014 to 2018 ( $\mathrm{Li}$ et al., 2019) or in 36 selected journals published from 2000 to 2018 (Li et al., 2020). The strong scholarship development in the USA is likely due to a research environment that is well supported and conducive to high research output. Studying public funding support for STEM education research in the USA will provide information on trends and patterns, which will be valuable both in the USA and in other countries.

\section{The context of policy and public funding support to STEM education in the USA}

The tremendous development of STEM education in the USA over the past decades has benefited greatly from both national policies and strong funding support from the US governmental agencies as well as private funding sources. Federal funding for research and development in science, mathematics, technology, and engineeringrelated education in the USA was restarted in the late 1980 s, in the latter years of the Reagan administration, which had earlier halted funding. In recent years, the federal government has strongly supported STEM education research and development. For example, the Obama administration in the USA (The White House, 2009) launched the "Educate to Innovate" campaign in November 2009 for excellence in STEM education as a national priority, with over 260 million USD in financial and in-kind support commitment. The Trump administration has continued to emphasize STEM education. For example, President Trump signed a memorandum in 2017 to direct ED to spend 200 million USD per year on competitive grants promoting STEM (The White House, 2017). In response, ED awarded 279 million USD in STEM discretionary grants in Fiscal Year 2018 (US 
Department of Education, 2018). The Trump administration took a step further to release a report in December 2018 detailing its five-year strategic plan of boosting STEM education in the USA (The White House, 2018). The strategic plan envisions that "All Americans will have lifelong access to high-quality STEM education and the USA will be the global leader in STEM literacy, innovation, and employment." (Committee on STEM Education, 2018, p. 1). Consistently, current Secretory of Education DeVos in the Trump administration has taken STEM as a centerpiece of her comprehensive education agenda (see https://www.ed.gov/stem). The consistency in national policies and public funding support shows that STEM education continues to be a strategic priority in the USA.

Among many federal agencies that funded STEM education programs, the ED and NSF have functioned as two primary agencies. For ED, the Institute of Education Sciences (Institute of Education Sciences (IES), n.d., see https://ies.ed.gov/aboutus/) was created by the Education Sciences Reform Act of 2002 as its statistics, research, and evaluation arm. ED's support to STEM education research has been mainly administered and managed by IES since 2003. In contrast to the focus of ED on education, NSF (see https://www.nsf.gov/about/) was created by Congress in 1950 to support basic research in many fields such as mathematics, computer sciences, and social sciences. Education and Human Resources is one of its seven directorates that provides important funding support to STEM education programs and research. In addition to these two federal agencies, some other federal agencies also provide funding support to STEM education programs and research from time to time.

Any study of public funding support to STEM education research in the USA would need to limit its scope, given the complexity of various public funding sources available in the system, the ambiguity associated with the meaning of STEM education across different federal agencies ( $\mathrm{Li}$ et al., 2020), and the number of programs that have funded STEM education research over the years. For the purpose of this review, we have chosen to focus on the projects in STEM education funded by IES.

\section{Research questions}

Given the preceding research approach decision to focus on research projects funded by IES, we generated the following questions:

1. What were the number of projects, total project funding, and the average funding per project from 2003 to 2019 in STEM education research?

2. What were the trends of having single versus multiple principal investigator(s) in STEM education?

3. What were the types of awardees of the projects?

4. What were the participant populations in the projects?

5. What were the types of projects in terms of goals for program development and research in STEM education?

6. What were the disciplinary foci of the projects?

7. What research methods did projects tend to use in conducting STEM education research?

\section{Method}

Based on the above discussion to focus on funding support from IES, we first specified the time period, and then searched the IES website to identify STEM

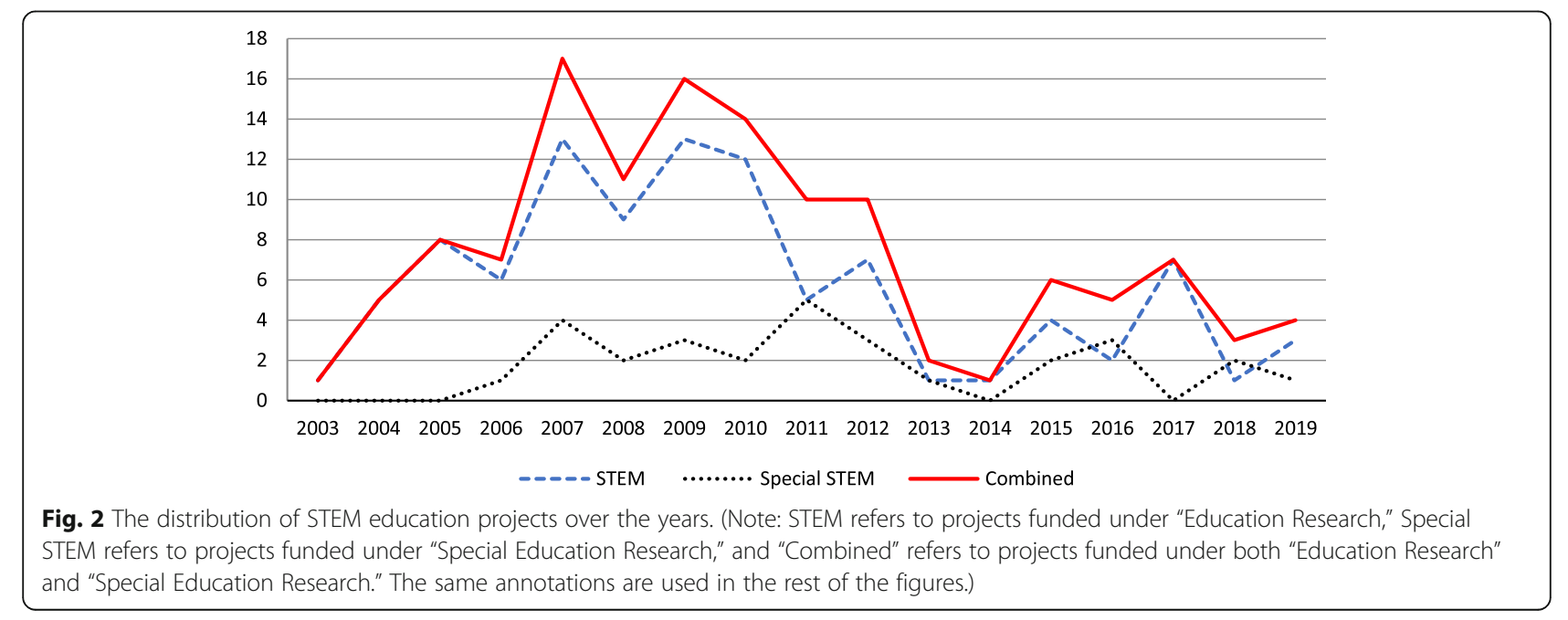




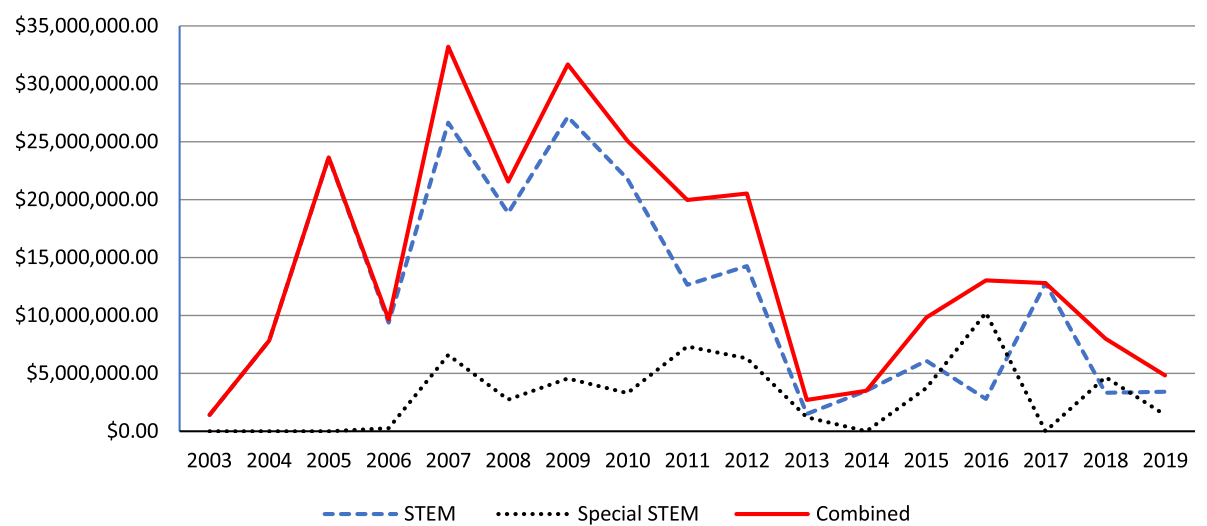

Fig. 3 Annual funding totals

education research projects funded by IES within the specified time period.

\section{Time period}

As discussed above, IES was established in 2002 and it did not start to administer and manage research funding support for ED until 2003. Therefore, we considered IES funded projects from 2003 to the end of 2019.

\section{Searching and identifying IES funded projects in STEM education}

Given the diverse perspectives about STEM education across different agencies and researchers (Li et al., 2020), we did not discuss and define the meaning of STEM education. Instead, we used the process described in the following paragraph to identify STEM education research projects funded by IES.

On the publicly accessible IES website (https://ies. ed.gov), one menu item is "FUNDING OPPORTUNITIES", and there is a list of choices within this menu item. One choice is "SEARCH FUNDED RESEARCH GRANTS AND CONTRACTS." On this web search page, we can choose "Program" under "ADDITIONAL SEARCH OPTIONS." There are two program categories related to STEM under the option of "Program." One is "Science, Technology, Engineering, and Mathematics (STEM) Education" under one large category of "Education Research" and the other is "Science, Technology, Engineering, and Mathematics" under another large category of "Special Education Research." We searched for funded projects under these two program categories, and the process returned 98 funded projects in "Science, Technology, Engineering, and Mathematics (STEM) Education" under "Education Research" and 29 funded projects in "Science, Technology, Engineering, and Mathematics" under "Special Education Research," for a total of 127 funded projects in these two programs designated for STEM education by IES ${ }^{1}$.

\section{Data analysis}

To address questions 1, 2, 3, and 4, we collected the following information about these projects identified using above procedure: amount of funding, years of duration, information about the PI, types of awardees that received and administered the funding (i.e., university versus those nonuniversity including non-profit organization such as WestEd, Educational Testing Service), and projects' foci on school level and participants. When a project's coverage went beyond one category, the project was then coded in terms of its actual number of categories being covered. For example, we used the five categories to classify project's participants: Pre-K, grades $1-4$, grades $5-8$, grades $9-12$, and adult. If a funded project involved participants from Pre-school to grade 8 , then we coded the project as having participants in three categories: Pre- $\mathrm{K}$, grades $1-4$, and grades $5-8$.

To address question 5, we analyzed projects based on goal classifications from IES. IES followed the classification of research types that was produced through a joint effort between IES and NSF in 2013 (Institute of Education Sciences (IES) and National Science Foundation (NSF), 2013). The effort specified six types of research that provide guidance on the goals and level of funding support: foundational research, early-stage or

\footnotetext{
${ }^{1}$ In a previous study (Wang, Li, \& Xiao, 2019), we used the acronym "STEM" as a search term under the option of "SEARCH FUNDED RESEARCH GRANTS AND CONTRACTS" without any program category restriction, and identified and analyzed 46 funded projects from 2007 to 2018 that contain "STEM" in a project's title and/or description after screening out unrelated key words containing "stem" such as "system". To make comparisons when needed, we did the same search using the acronym "STEM" and found 8 more funded projects in 2019 for a total of 54 funded projects across many different program categories from 2007 to 2019.
} 


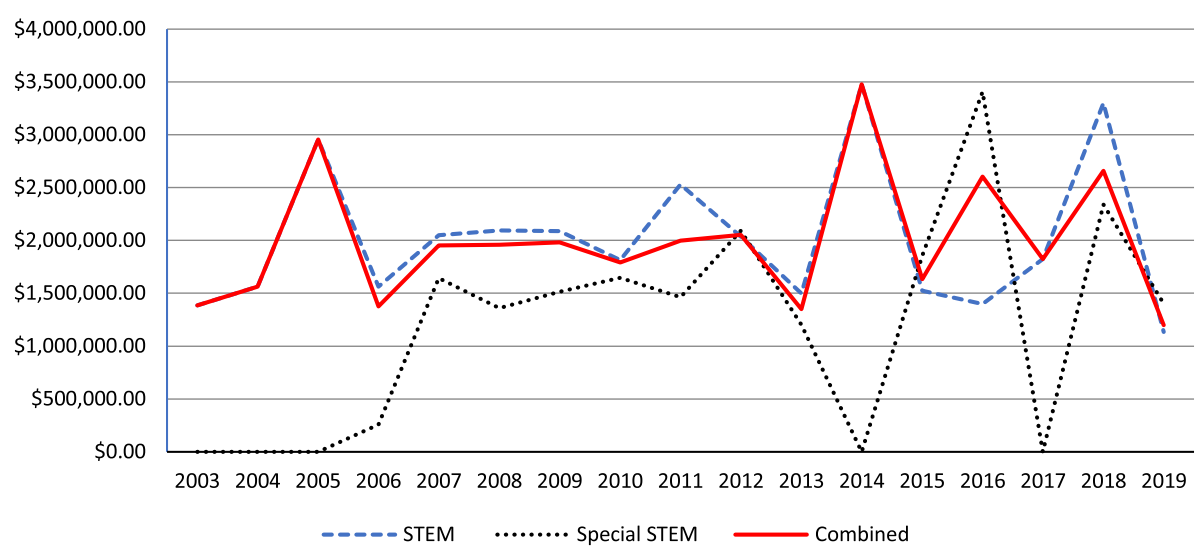

Fig. 4 The trend of average funding amount per project funded each year in STEM education research

exploratory research, design and development research, efficacy research, effectiveness research, and scale-up research. Related to these types, IES classified goals for funded projects: development and innovation, efficacy and replication, exploration, measurement, and scale-up evaluation, as described on the IES website.

To address question 6 , we coded the disciplinary focus using the following five categories: mathematics, science, technology, engineering, and integrated (meaning an integration of any two or more of STEM disciplines). In some cases, we coded a project with multiple disciplinary foci into more than one category. The following are two project examples and how we coded them in terms of disciplinary foci:

(1). The project of "A Randomized Controlled Study of the Effects of Intelligent Online Chemistry Tutors in Urban California School Districts" (2008, https://ies.ed.gov/funding/grantsearch/ details.asp?ID=601) was to test the efficacy of the Quantum Chemistry Tutors, a suite of computerbased cognitive tutors that are designed to give individual tutoring to high school students on 12 chemistry topics. Therefore, we coded this project as having three categories of disciplinary foci: science because it was chemistry, technology because it applied instructional technology, and integrated because it integrated two or more of STEM disciplines.

(2). The project of "Applications of Intelligent Tutoring Systems (ITS) to Improve the Skill Levels of Students with Deficiencies in Mathematics" (2009, https://ies. ed.gov/funding/grantsearch/details.asp? $I D=827$ ) was coded as having three categories of disciplinary foci: mathematics, technology because it used intelligent tutoring systems, and integrated because it integrated two or more of STEM disciplines.
To address question 7, all 127 projects were coded using a classification category system developed and used in a previous study (Wang et al., 2019). Specifically, each funded project was coded in terms of research type (experimental, interventional, longitudinal, single case, correlational $^{2}$, data collection method (interview, survey, observation, researcher designed tests, standardized tests, computer data ${ }^{3}$ ), and data analysis method (descriptive statistics, ANOVA*, general regression, HLM, IRT, SEM, others $)^{4}$. Based on a project description, specific method(s) were identified and coded following a procedure similar to what we used in a previous study (Wang et al., 2019). Two researchers coded each project's description, and the agreement between them for all 127 projects was $88.2 \%$. When method and disciplinary focus-coding discrepancies occurred, a final decision was reached after discussion.

\section{Results and discussion}

In the following sections, we report findings as corresponding to each of the seven research questions.

\footnotetext{
${ }^{2}$ The project of "A Randomized Controlled Study of the Effects of Intelligent Online Chemistry Tutors in Urban California School Districts" (2008). In the project description, its subtitle shows intervention information. We coded this project as "interventional." Then, the project also included the treatment group and the control group. We coded this project as "experimental." Finally, this project was to test the efficacy of computer-based cognitive tutors. This was a correlational study. We thus coded it as "correlational."

${ }^{3}$ Computer data means that the project description indicated this kind of information, such as log data on students.

${ }^{4}$ Descriptive means "descriptive statistics." General regression means multiple regression, linear regression, logistical regression, except hierarchical linear regression model. ANOVA* is used here as a broad term to include analysis of variance, analysis of covariance, multivariate analysis of variance, and/or multivariate analysis of variance. Others include factor analysis, $t$ tests, Mann-Whitney tests, and binomial tests, log data analysis, meta-analysis, constant comparative data analysis, and qualitative analysis.
} 


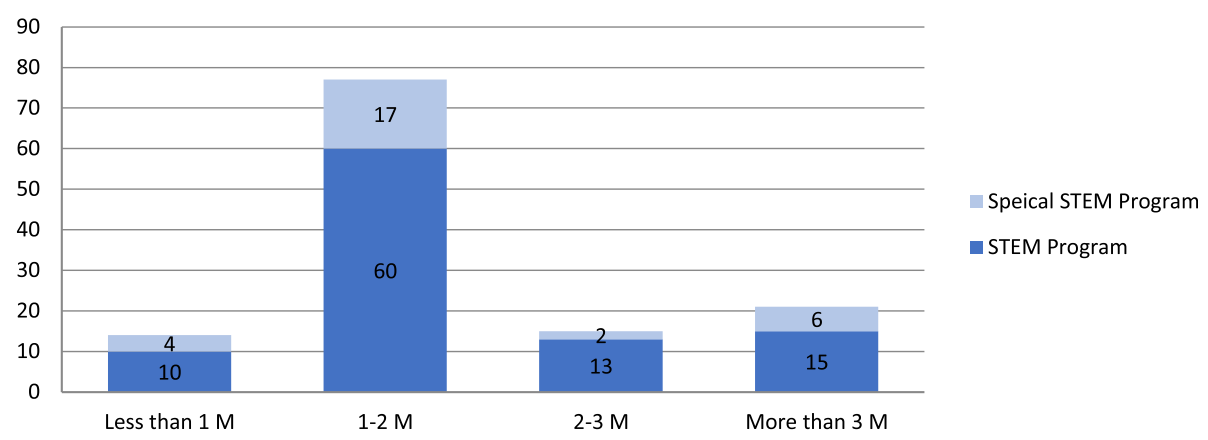

Fig. 5 The number of projects in terms of total funding amount categories

Question 1: the number of projects, total funding, and the average funding per project from 2003 to 2019

Figure 2 shows the distribution of funded projects over the years in each of the two program categories, "Education Research" and "Special Education Research," as well as combined (i.e., "STEM" for projects funded under "Education Research," "Special STEM" for projects funded under "Special Education Research," and "Combined" for projects funded under both "Education Research" and "Special Education Research"). As Fig. 2 shows, the number of projects increased each year up to 2007, with STEM education projects started in 2003 under "Education Research" and in 2006 under "Special Education Research." The number of projects in STEM under "Special Education Research" was generally less than those funded under the program category of "Education Research," especially before 2011. There are noticeable decreases in combined project counts from 2009 to 2011 and from 2012 to 2014, before the number count increased again in 2015. We did not find a consistent pattern across the years from 2003 to 2019.

A similar trend can be observed in the total funding amount for STEM education research (see Fig. 3). The figure shows noticeably big year-to-year swings from 2003 to 2019, with the highest funding amount of more than 33 million USD in 2007 and the lowest amount of 2,698,900 USD in 2013 from these two program categories. Although it is possible that insufficient high-quality grant proposals were available in one particular year to receive funding, the funded amount and the number of projects (Fig. 2) provide insights about funding trends over the time period of the review.

As there are diverse perspectives and foci about STEM education, we also wondered if STEM education research projects might be funded by IES but in program options other than those designated options of "Science, Technology, Engineering, and Mathematics (STEM) Education." We found a total of 54 funded projects from 2007 to 2019, using the acronym "STEM" as a search term under the option of "SEARCH FUNDED RESEARCH GRANTS AND CONTRACTS" without any program category restriction. Only $2(3.7 \%)$ out of these 54 projects were in the IES designated program options of STEM education in the category of "Education Research." Further information about these 54 projects and related discussion can be found as additional notes at the end of this review.

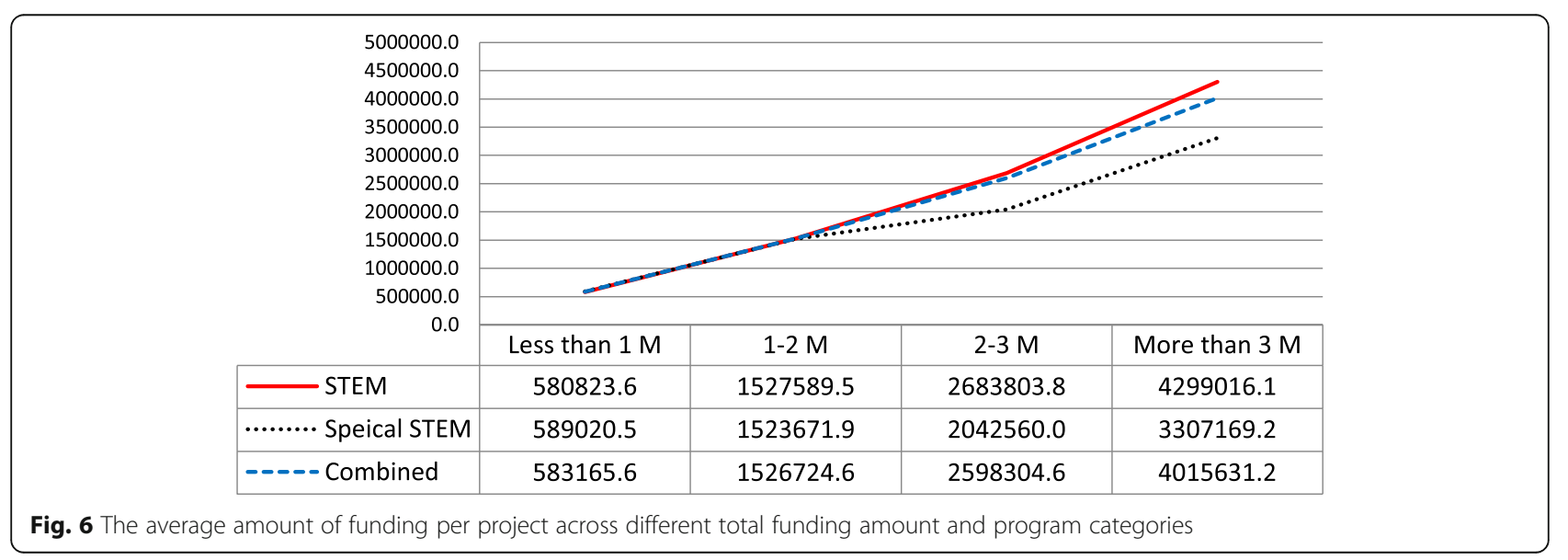




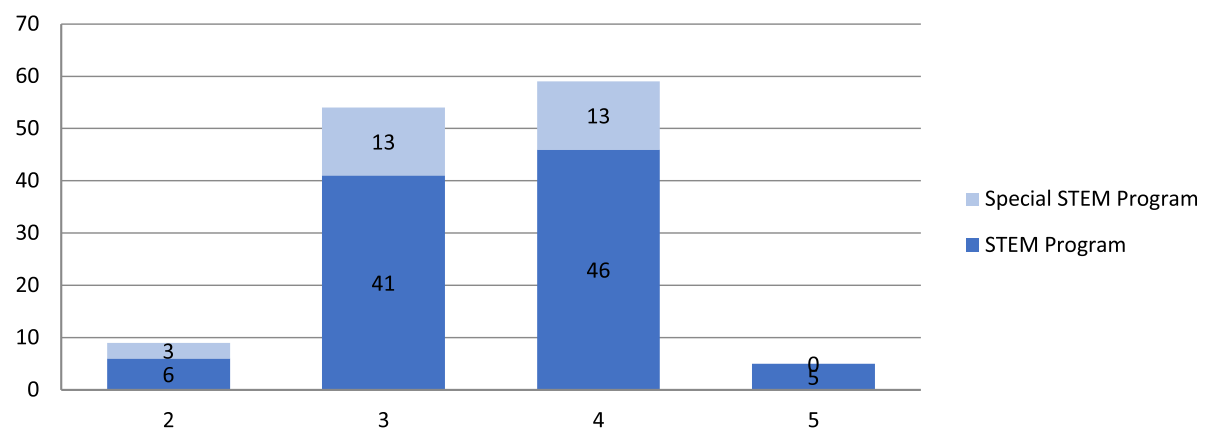

Fig. 7 The number of projects in terms of years of project duration. (Note, 2: 2-year projects; 3: 3-year projects; 4: 4-year projects; 5: 5-year projects)

Results from two different approaches to searching for IES-funded projects will likely raise questions about what kinds of projects were funded in the designated program option of "Science, Technology, Engineering, and Mathematics (STEM) Education," if only two funded projects under this option contained the acronym "STEM" in a project's title and/or description. We shall provide further information in the following subsections, especially when answering question 6 related to projects' disciplinary focus.

Figure 4 illustrates the trend of average funding amount per project each year in STEM education research from 2003 to 2019. The average funding per project varied considerably in the program category "Special Education Research," and no STEM projects were funded in 2014 and 2017 in this category. In contrast, average funding per project was generally within the range of $1,132,738$ USD in 2019 to $3,475,975$ USD in 2014 for the projects in the category of "Education Research" and also for project funding in the combined category.
Figure 5 shows the number of projects in different funding amount categories (i.e., less than 1 million USD, 1-2 million USD, 2-3 million USD, 3 million USD or more). The majority of the 127 projects obtained funding of 1-2 million USD (77 projects, $60.6 \%$ ), with 60 out of 98 projects (61.2\%) under "Education Research" program and 17 out of 29 projects (58.6\%) in the program category "Special Education Research." The category with second most projects is funding of 3 million USD or more (21 projects, $16.5 \%)$, with 15 projects $(15.3 \%$ of 98 projects) under "Education Research" and 6 projects $(20.7 \%$ of 29 projects) under "Special Education Research."

Figure 6 shows the average amount of funding per project funded across these different funding amount and program categories. In general, the projects funded under "Education Research" tended to have a higher average amount than those funded under "Special Education Research," except for those projects in the total funding amount category of "less than 1 million USD." Considering all 127 funded projects, the

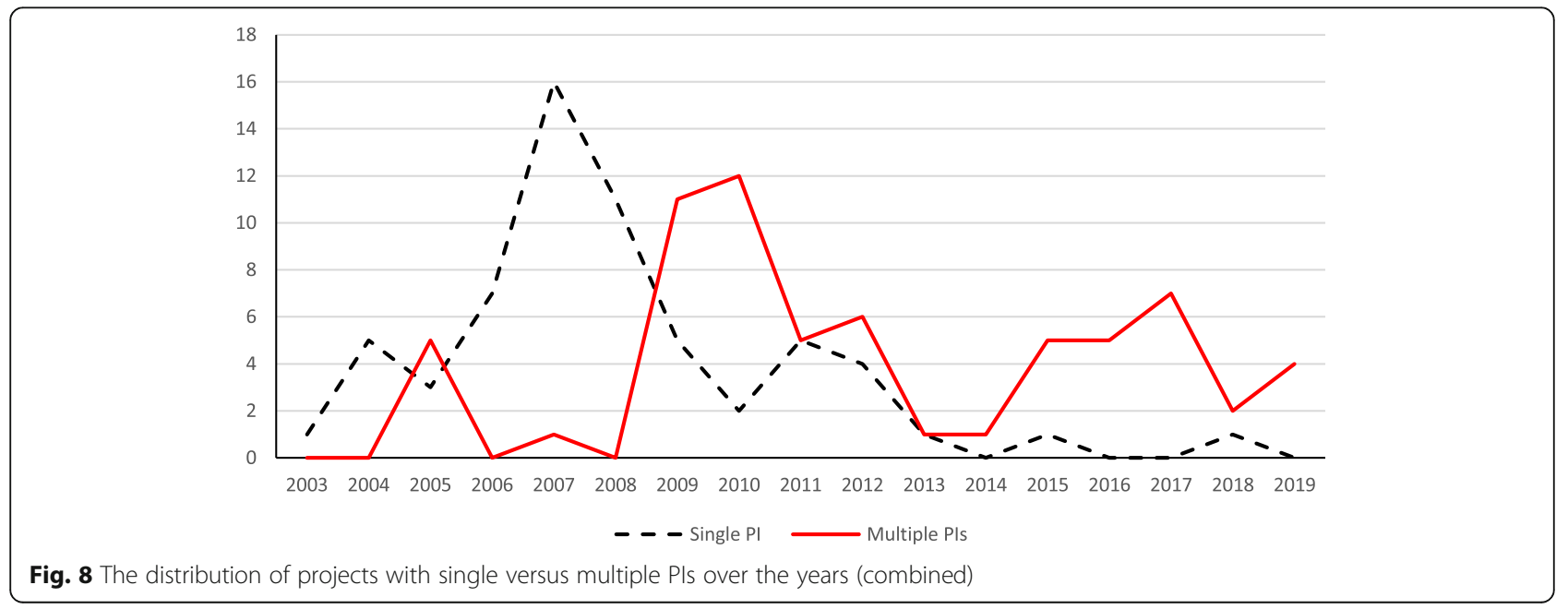




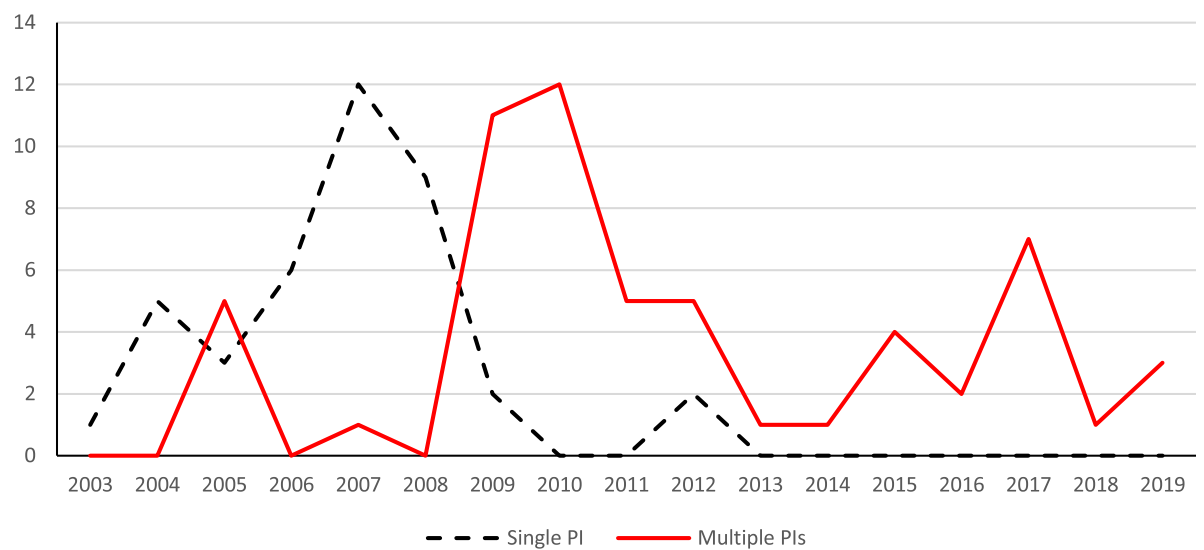

Fig. 9 The distribution of projects with single versus multiple Pls over the years (in "Education Research" program)

average amount of funding was 1,960,826.3 USD per project.

Figure 7 shows that the vast majority of these 127 projects were 3- or 4-year projects. In particular, 59 (46.5\%) projects were funded as 4-year projects, with 46 projects (46.9\%) under "Education Research" and 13 projects (44.8\%) under "Special Education Research." This category is followed closely by 3 -year projects (54 projects, $42.5 \%)$, with 41 projects (41.8\%) under "Education Research" and 13 projects (44.8\%) under "Special Education Research."

\section{Question 2: trends of single versus multiple principal investigator(s) in STEM education}

Figure 8 shows the distribution of projects over the years grouped by a single PI or multiple PIs where the program categories of "Education Research" and "Special Education Research" have been combined. The majority of projects before 2009 had a single PI, and the trend has been to have multiple PIs for STEM education research projects since 2009. The trend illustrates the increased emphases on collaboration in STEM education research, which is consistent with what we learned from a recent study of journal publications in STEM education (Li et al., 2020).

Separating projects by program categories, Fig. 9 shows projects funded in the program category "Education Research." The trends of single versus multiple PIs in Fig. 9 are similar to the trends shown in Fig. 8 for the combined programs. In addition, almost all projects in STEM education funded under this regular research program had multiple PIs since 2010.

Figure 10 shows projects funded in the category "Special Education Research." The pattern in Fig. 10, where very few projects funded under this category had multiple PIs before 2014, is quite different from the patterns in Figs. 8 and 9. We did not learn if single PIs were appropriate for the nature of these projects. The trend started to change in 2015 as the number of projects with multiple PIs increased and the number of projects with single PIs declined.

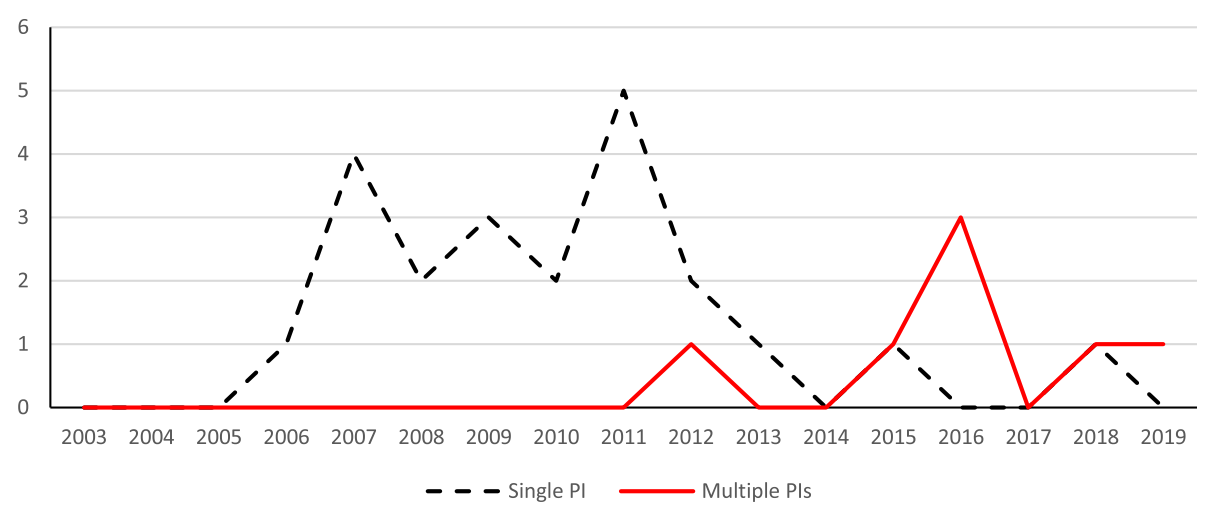

Fig. 10 The distribution of projects with single versus multiple Pls over the years (in "Special Education Research" program) 


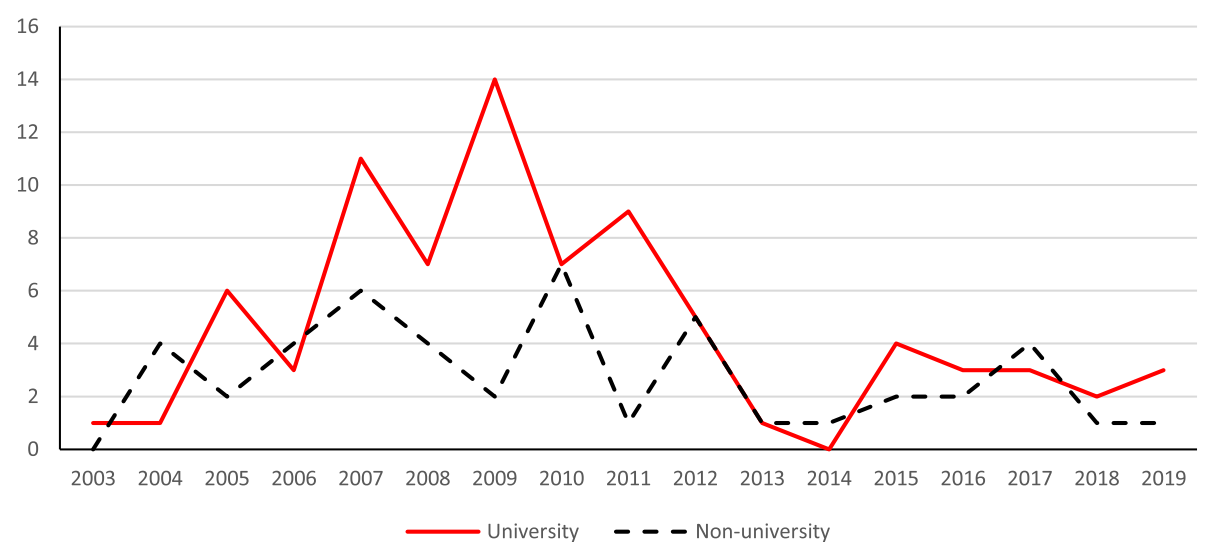

Fig. 11 The distribution of projects funded to university versus non-university awardees over the years

\section{Question 3: types of awardees of these projects}

Besides the information about the project's PI, the nature of the awardees can help illustrate what types of entity or organization were interested in developing and carrying out STEM education research. Figure 11 shows that the university was the main type of awardee before 2012, with $80(63.0 \%)$ projects awarded to universities from 2003 to 2019. At the same time, non-university entities received funding support for 47 (37.0\%) projects and they seem to have become even more active and successful in obtaining research funding in STEM education over the past several years. The result suggests that diverse organizations develop and conduct STEM education research, another indicator of the importance of STEM education research.

\section{Question 4: participant populations in the projects}

Figure 12 indicates that the vast majority of projects were focused on student populations in preschool to grade 12. This is understandable as IES is the research funding arm of ED. Among those projects, middle school students were the participants in the most projects (70 projects), followed by student populations in elementary school (48 projects), and high school (38 projects). The adult population (including postsecondary students and teachers) was the participant group in 36 projects in a combined program count.

If we separate "Education Research" and "Special Education Research" programs, projects in the category "Special Education Research" focused on student populations in elementary and middle school most frequently, and then adult population. In contrast, projects in the category "Education Research" focused most frequently on middle school student population, followed by student populations in high school and elementary school.
Given the importance of funded research in special education $^{5}$ at IES, we considered projects focused on participants with disabilities. Figure 13 shows there were 28 projects in the category "Special Education Research" for participants with disabilities. There were also three such projects funded in the category "Education Research," which together accounted for a total of 31 $(24.4 \%)$ projects. In addition, some projects in the category "Education Research" focused on other participants, including 11 projects focused on ELL students (8.7\%) projects and 37 projects focused on low SES students (29.1\%).

Figure 14 shows the trend of projects in STEM education for special participant populations. Participant populations with ELL and/or Low SES gained much attention before 2011 among these projects. Participant populations with disabilities received relatively consistent attention in projects on STEM education over the years. Research on STEM education with special participant populations is important and much needed. However, related scholarship is still in an early development stage. Interested readers can find related publications in this journal (e.g., Schreffler et al., 2019) and other journals (e.g., Lee, 2014).

\section{Question 5: types of projects in terms of goals for program development and research}

Figure 15 shows that "development and innovation" was the most frequently funded type of project (58 projects, $45.7 \%$ ), followed by "efficacy and replication" (34 projects, $26.8 \%$ ), and "measurement" (21 projects, 16.5\%). The pattern is consistent across "Education Research," "Special Education Research," and combined. However, it should be noted that all five projects with the goal of

${ }^{5}$ Special education originally was about students with disabilities. It has broadened in scope over the years. 


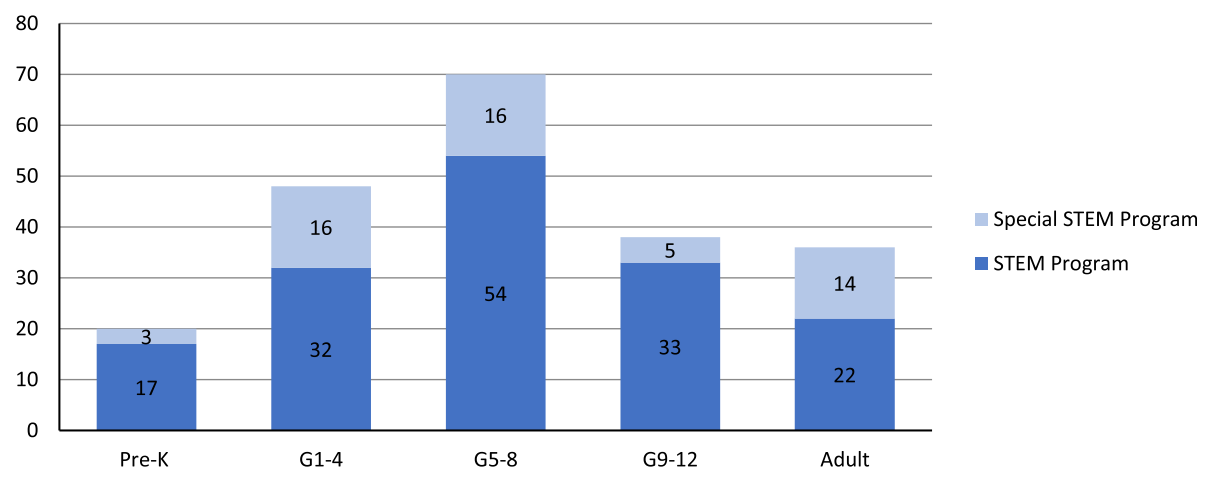

Fig. 12 The number of projects in STEM education for different groups of participants (Note: Pre-K: preschool-kindergarten; G1-4: grades 1-4; G5-8: grades 5-8; G9-12: grades 9-12; adult: post-secondary students and teachers)

"scale-up evaluation" were in the category "Education Research" and funding for these projects were large.

Examining the types of projects longitudinally, Fig. 16 shows that while "development and innovation" and "efficacy and replication" types of projects were most frequently funded in the "Education Research" program, the types of projects being funded changed longitudinally. The number of "development and innovation" projects was noticeably fewer over the past several years. In contrast, the number of "measurement" projects and "efficacy and replication" projects became more dominant. The change might reflect a shift in research development and needs.

Figure 17 shows the distribution of project types in the category "Special Education Research." The pattern is different from the pattern shown in Fig. 16. The types of "development and innovation" and "efficacy and replication" projects were also the dominant types of projects under "Special Education Research" program category in most of these years from 2007 to 2019. Projects in the type "measurement" were only observed in 2010 when that was the only type of project funded.

\section{Question 6: disciplinary foci of projects in developing and conducting STEM education research}

Figure 18 shows that the majority of the 127 projects under such specific programs included disciplinary foci on individual STEM disciplines: mathematics in 88 projects, science in 51 projects, technology in 43 projects, and engineering in 2 projects. The tremendous attention to mathematics in these projects is a bit surprising, as mathematics was

\footnotetext{
${ }^{6}$ The number of students under Special Education was 14\% of students in public schools in the USA in 2017-2018. https://nces.ed.gov/ programs/coe/indicator_cgg.asp
}

noted as being out of balance in STEM education (English, 2016) and also in STEM education publications (Li, 2018b, 2019). As noted above, each project can be classified in multiple disciplinary foci. However, of the 88 projects with a disciplinary focus on mathematics, 54 projects had mathematics as the only disciplinary focus (38 under "Education Research" program and 16 under "Special Education Research" program). We certainly hope that there will be more projects that further scholarship where mathematics is included as part of (integrated) STEM education (see Li \& Schoenfeld, 2019).

There were also projects with specific focus on integrated STEM education (i.e., combining any two or more disciplines of STEM), with a total of 55 (43.3\%) projects in a combined program count. The limited number of projects on integrated STEM in the designated STEM funding programs further confirms the common perception that the development of integrated STEM education and research is still in its initial stage (Honey et al., 2014; Li, 2018a).

In examining possible funding trends, Fig. 19 shows that mathematics projects were more frequently funded before 2012. Engineering was a rare disciplinary focus. Integrated STEM was a disciplinary focus from time to time among these projects. No other trends were observed.

\section{Question 7: research types and methods that projects used}

Figure 20 indicates that "interventional" (in 104 projects, $81.9 \%$ ) and "experimental research" (in 89 projects, $70.1 \%$ ) were the most frequently funded types of research. The percentages of projects funded under the regular education research program were similar to those funded under "Special Education Research" program, except that projects funded under "Special 


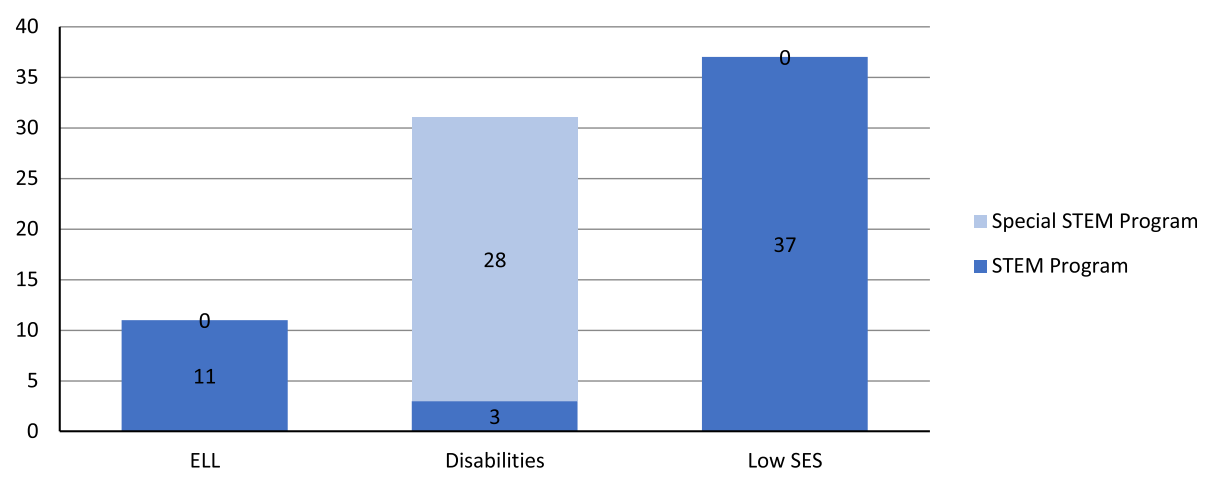

Fig. 13 The number of funded projects in STEM education for three special participant populations (Note: ELL: English language learners, Low SES: low social-economic status)

Education Research" tended to utilize correlational research more often.

Research in STEM education uses diverse data collection and analysis methods; therefore, we wanted to study types of methods (Figs. 21 and 22, respectively). Among the six types of methods used for data collection, Fig. 21 indicates that "standardized tests" and "designed tests" were the most commonly used methods for data collection, followed by "survey," "observation," and "interview." The majority of projects used three quantitative methods ("standardized tests," "researcher designed tests," and "survey"). The finding is consistent with the finding from analysis of journal publications in STEM education ( $\mathrm{Li}$ et al., 2020). Data collected through "interview" and "observation" were more likely to be analyzed using qualitative methods as part of a project's research methodology.

Figure 22 shows the use of seven (including others) data analysis methods among these projects. The first six methods (i.e., descriptive, ANOVA*, general regression, HLM, IRT, and SEM) as well as some methods in "others" are quantitative data analysis methods. The number of projects that used these quantitative methods is considerably larger than the number of projects that used qualitative methods (i.e., included in "others" category).

\section{Concluding remarks}

The systematic analysis of IES-funded research projects in STEM education presented an informative picture about research support for STEM education development in the USA, albeit based on only one public funding agency from 2003 to 2019. Over this 17-year span, IES funded 127 STEM education research projects (an average of over seven projects per year) in two designated STEM program categories. Although we found no discernable longitudinal funding patterns in these two program categories, both the number of funded projects in STEM education and their funding amounts were high. If we included an additional 52 projects with the acronym "STEM" funded by many other programs from 2007 to 2019

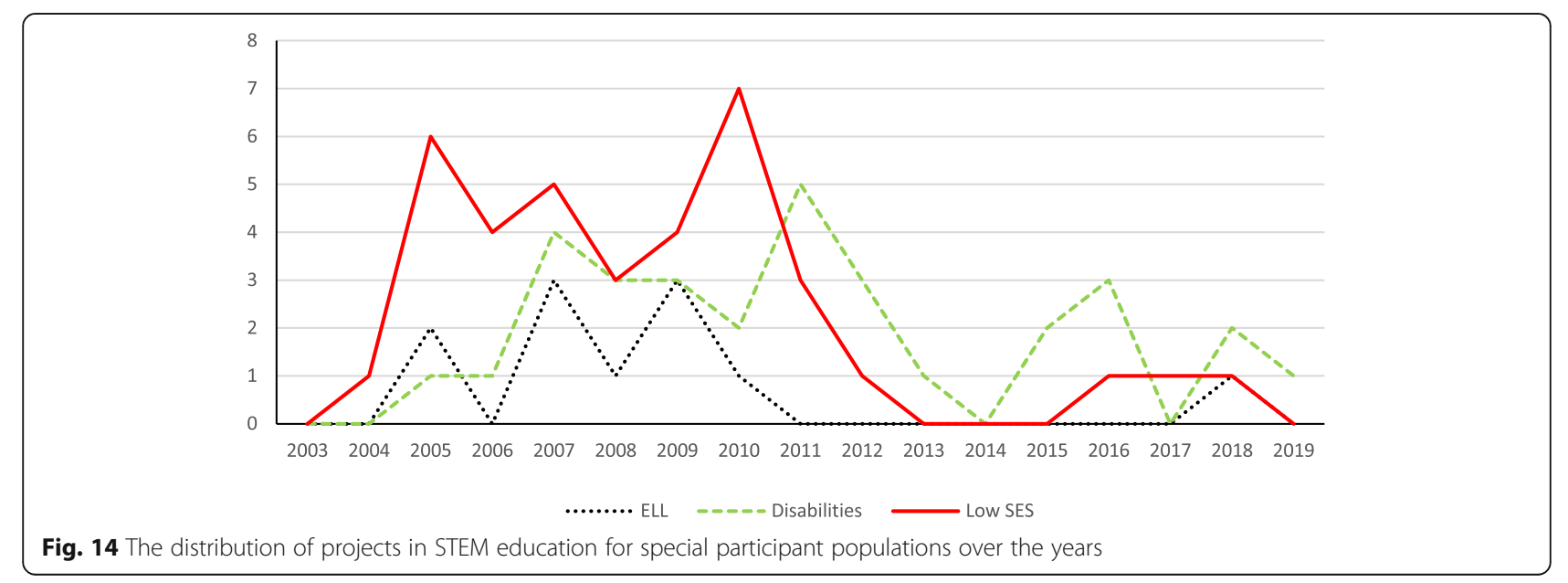




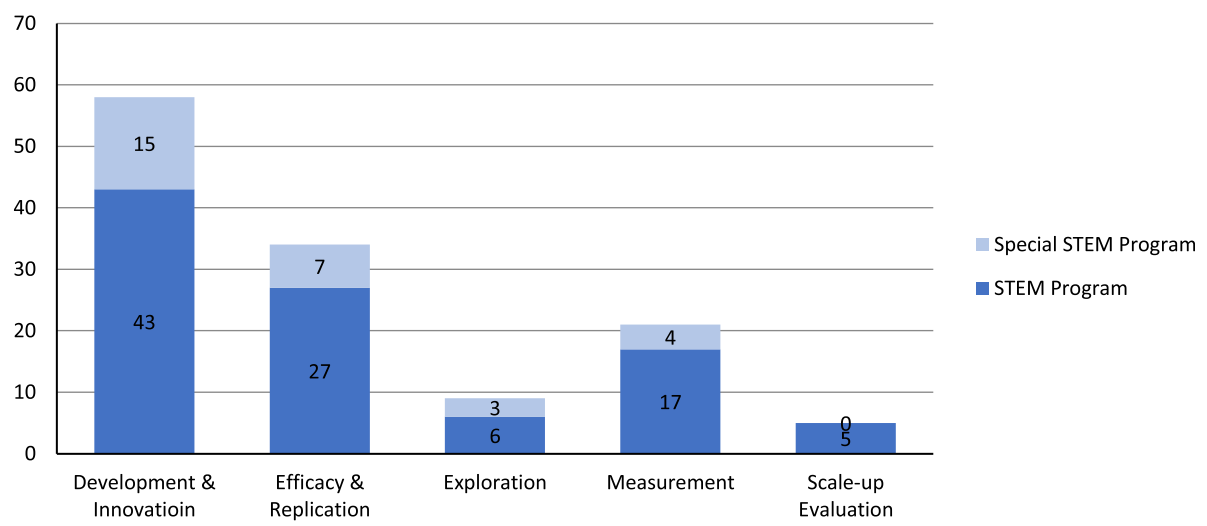

Fig. 15 The number of projects in terms of the types of goals

(see "Notes" section below), the total number of projects in STEM education research would be even higher, and the number of projects with the acronym "STEM" would also be larger. The results suggested the involvement of many researchers with diverse expertise in STEM education research was supported by a broad array of program areas in IES.

Addressing the seven questions showed several findings. Funding support for STEM education research was strong, with an average of about 2 million USD per project for a typical 3-4 year duration. Also, our analysis showed that the number of projects with multiple PIs over the years increased over the study time period, which we speculate was because STEM education research increasingly requires collaboration. STEM education research is still in early development stage, evidenced by the predominance of project goals in either "development and innovation" or "efficacy and replication" categories. We found very few projects (5 out of 127 projects, $4.0 \%)$ that were funded for "scale-up evaluation." Finally, as shown by our analysis of project participants, IES had focused on funding projects for students in grades 1-12. Various quantitative research methods were frequently used by these projects for data collection and analyses.

These results illustrated how well STEM education research was supported through both the designated STEM education and many other programs during the study time period, which helps to explain why researchers in the USA have been so productive in producing and promoting scholarship in STEM education ( $\mathrm{Li}$ et al., 2019; $\mathrm{Li}$ et al., 2020). We connected several findings from this study to findings from recent reviews of journal publications in STEM education. For example, publications in STEM

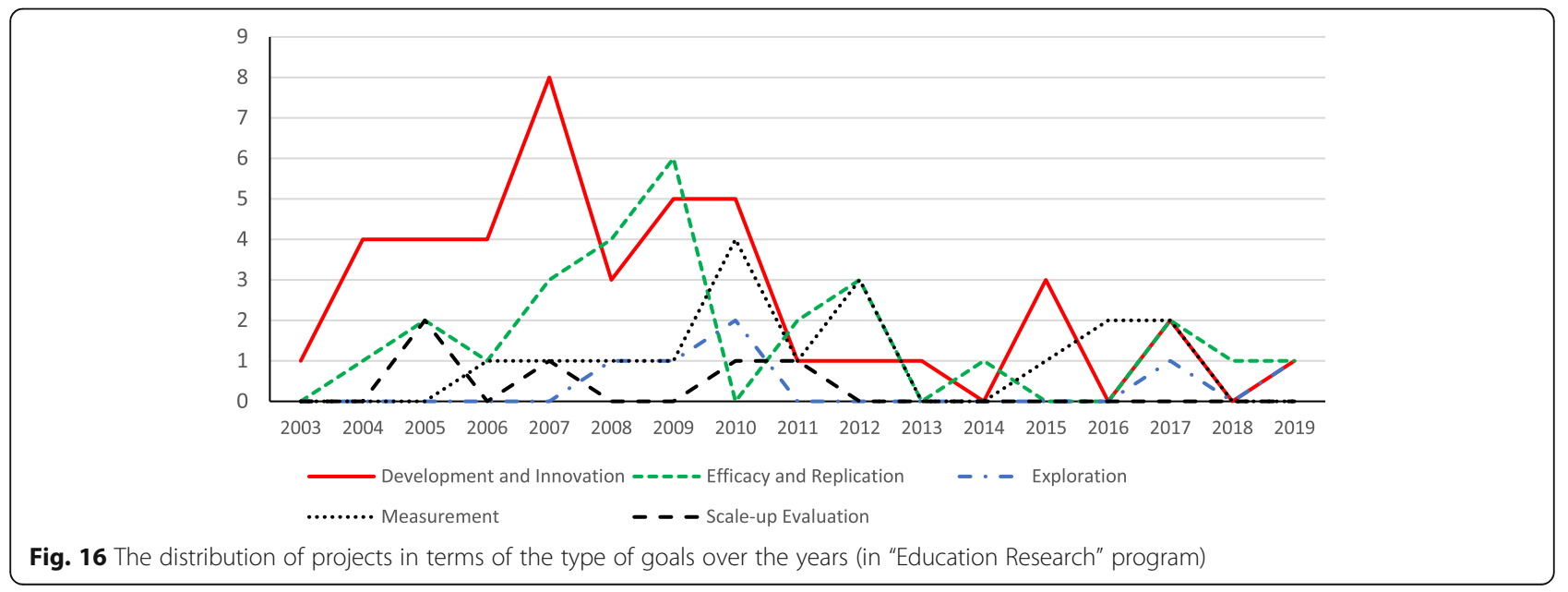




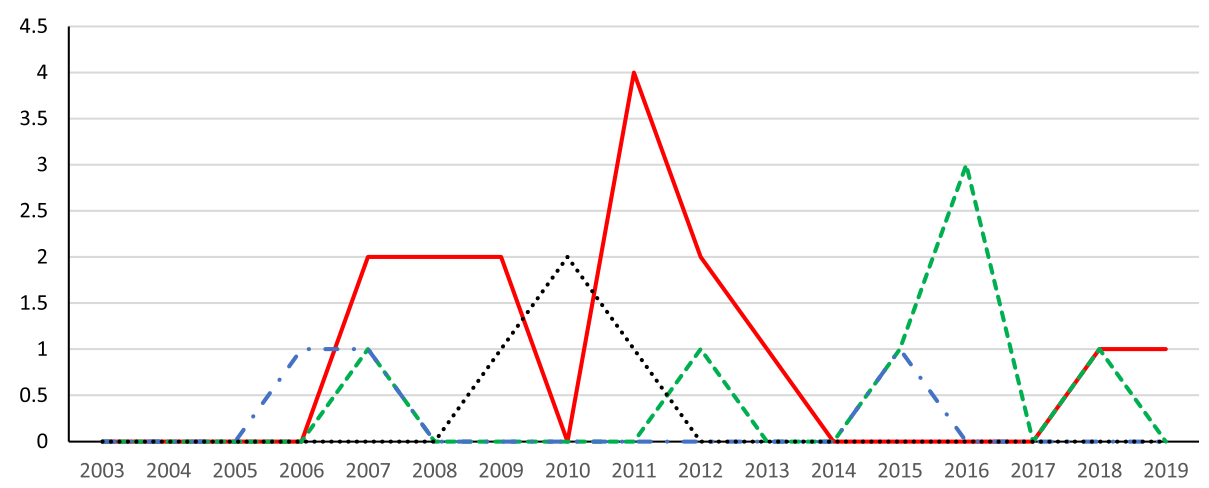

Fig. 17 The distribution of projects in terms of goals over the years (in "Special Education Research" program)

education appeared in many different journals as many researchers with diverse expertise were supported to study various issues related to STEM education, STEM education publications often have co-authorship, and there is heavy use of quantitative research methods. The link between public funding and significant numbers of publications in STEM education research from US scholars offers a strong argument for the importance of providing strong funding support to research and development in STEM education in the USA and also in many other countries around the world.

The systematic analysis also revealed that STEM education, as used by IES in naming the designated programs, did not convey a clear definition or scope. In fact, we found diverse disciplinary foci in these projects. Integrated STEM was not a main focus of these designated programs in funding STEM education. Instead, many projects in these programs had clear subject content focus in individual disciplines, which is very similar to discipline-based education research (DBER, National Research Council, 2012). Interestingly enough, STEM education research had also been supported in many other programs of IES with diverse foci", such as "Small

\footnotetext{
${ }^{7}$ For example, "Design Environment for Educator-Student Collaboration Allowing Real-Time Engineering-centric, STEM (DESCARTES) Exploration in Middle Grades" (2017) was funded as a 2-year project to Parametric Studios, Inc. (awardee) under the program option of "Small Business Innovation Research" (here is the link: https://ies.ed. gov/funding/grantsearch/details.asp?ID=1922). "Exploring the Spatial Alignment Hypothesis in STEM Learning Environments" (2017) was funded as a 4-year project to WestEd (awardee) under the program option of "Cognition and Student Learning" (link: https://ies.ed.gov/ funding/grantsearch/details.asp?ID=2059). "Enhancing Undergraduate STEM Education by Integrating Mobile Learning Technologies with Natural Language Processing" (2018) was funded as a 4-year project to Purdue University (awardee) under the program option of "Postsecondary and Adult Education" (link: https://ies.ed.gov/funding/grantsearch/details.asp?ID=2130).
}

Business Innovation Research," "Cognition and Student Learning," and "Postsecondary and Adult Education." This funding reality further suggested the broad scope of issues associated with STEM education, as well as the growing need of building STEM education research as a distinct field (Li, 2018a).

Inspired by our recent review of journal publications as research output in STEM education, this review started with an ambitious goal to study funding support as research input for STEM education. However, we had to limit the scope of the study for feasibility. We limited funding sources to one federal agency in the USA. Therefore, we did not analyze funding support from private funding sources including many private foundations and corporations. Although public funding sources have been one of the most important funding supports available for researchers to develop and expand their research work, the results of this systematic analysis suggest the importance future studies to learn more about research support and input to STEM education from other sources including other major public funding agencies, private foundations, and non-profit professional organizations.

\section{Notes}

Among these 54 funded projects containing the acronym "STEM" from 2007 to 2019, Table 1 shows that only $2(3.7 \%)$ were in the IES designated program option of STEM education in the category of "Education Research." Forty-nine projects were in 13 other program options in the category of "Education Research," with surprisingly large numbers of projects under the "Small Business Innovation Research" option (17, 31.5\%) and "Cognition and Student Learning" (11, 


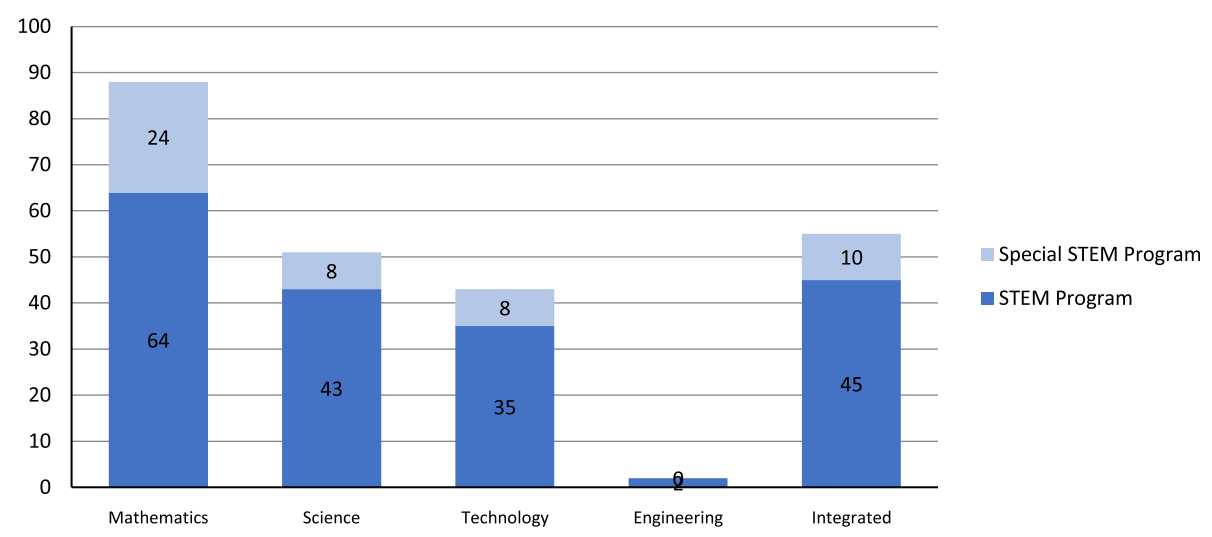

Fig. 18 The number of projects in terms of disciplinary focus

20.4\%). Three of the 54 funded projects were in the program category of "Special Education Research." To be specific, two of the three were in the program of "Small Business Innovation Research in Special Education," and one was in the program of "Special Topic: Career and Technical Education for Students with Disabilities."

The results suggest that many projects, focusing on various issues and questions directly associated with STEM education, were funded even when researchers applied for funding support in program options not designated as "Science, Technology, Engineering, and Mathematics (STEM) Education." It implies that issues associated with STEM education had been generally acknowledged as important across many different program areas in education research and special education research. The funding support available in diverse program areas likely allowed numerous scholars with diverse expertise to study many different questions and publish their research in diverse journals, as we noted in the recent review of journal publications in STEM education (Li et al., 2020).

A previous study identified and analyzed a total of 46 IES funded projects from 2007 to 2018 (with an average of fewer than 4 projects per year) that contain the acronym "STEM" in a project's title and/or description (Wang et al., 2019). Finding eight newly funded projects in 2019 suggested a growing interest in research on issues directly associated with STEM education in diverse program areas. In fact, five out of these eight newly funded projects specifically included the acronym "STEM" in the project's title to explicitly indicate the project's association with STEM education.

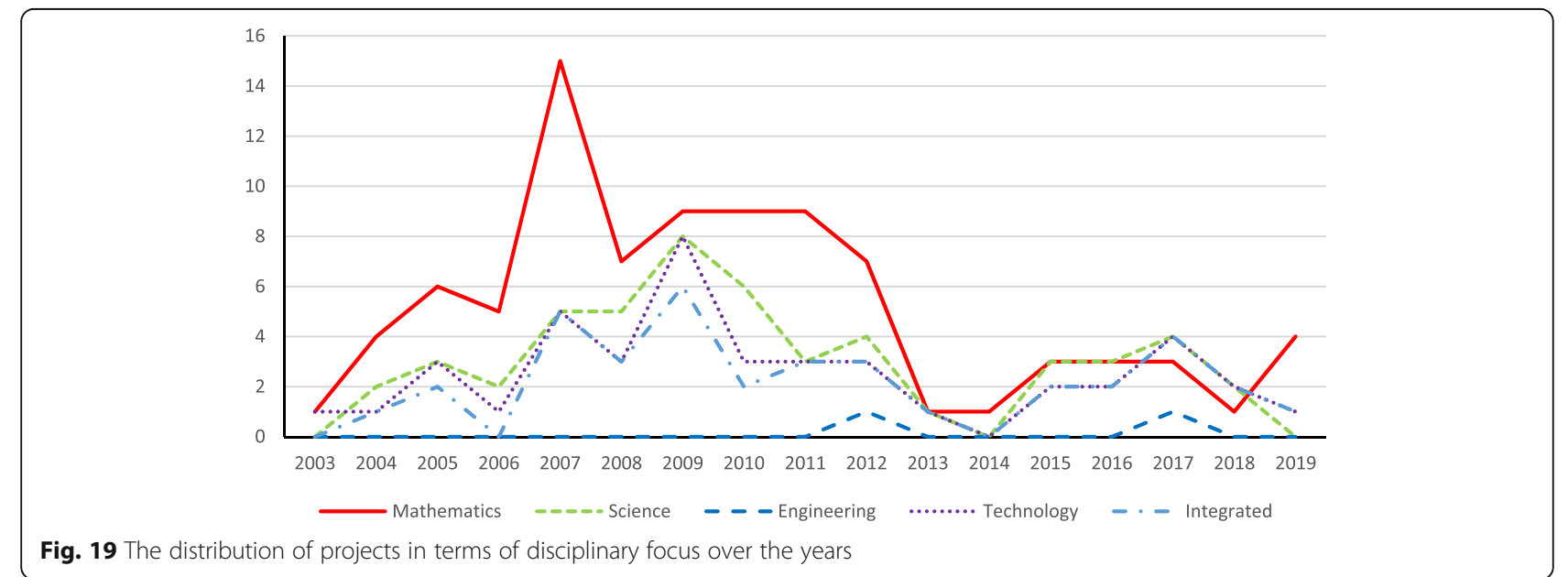

Fig. 19 The distribution of projects in terms of disciplinary focus over the years 


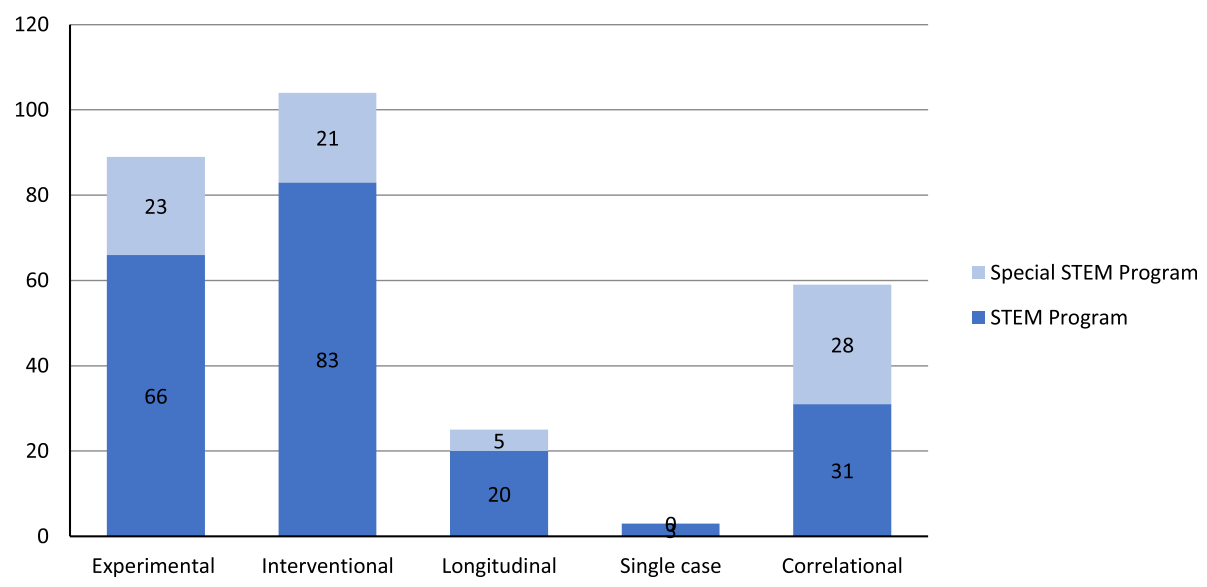

Fig. 20 The number of projects in terms of the type of research conducted

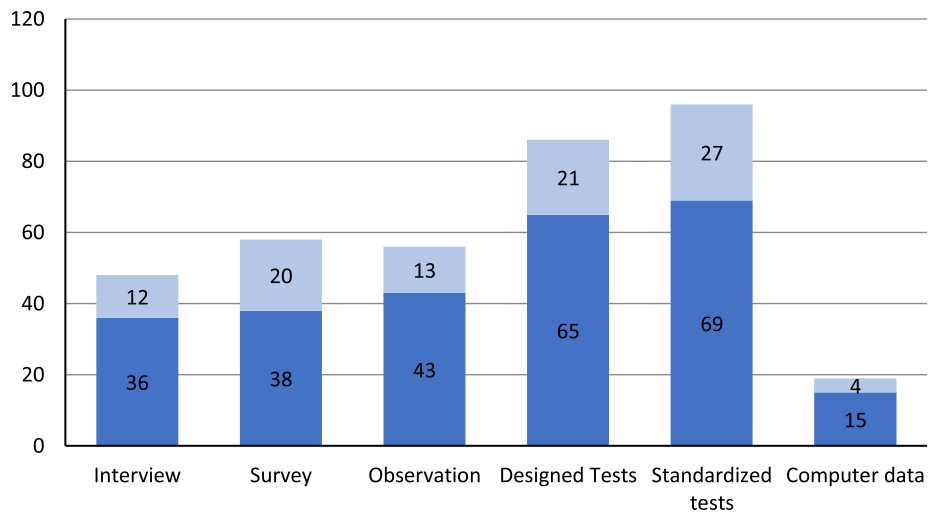

n Special STEM Program

- STEM Program

Fig. 21 The number of projects categorized by the type of data collection methods

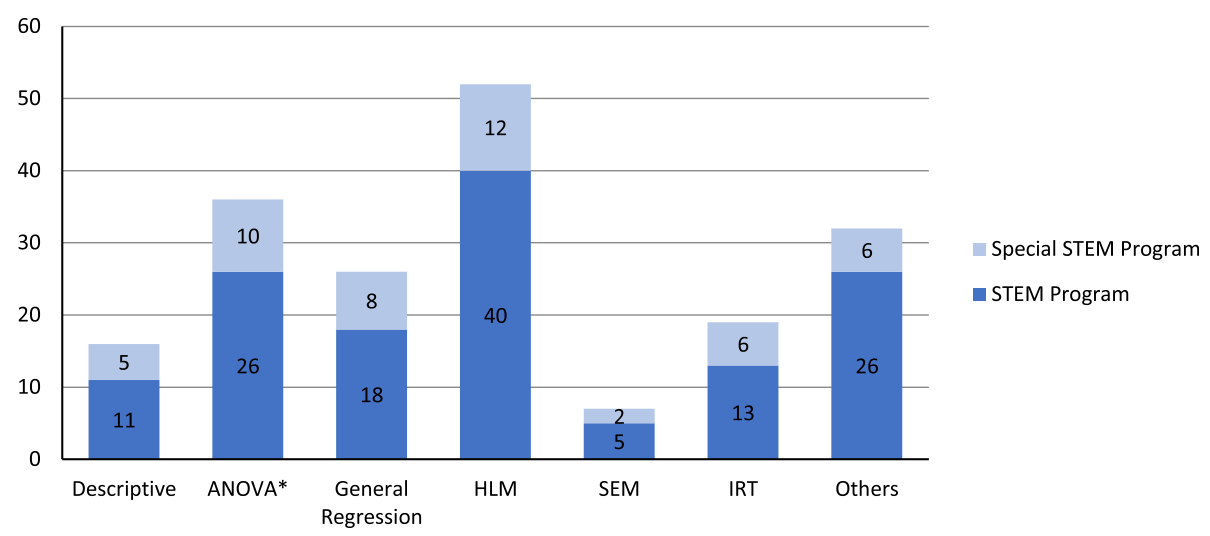

Fig. 22 The number of projects categorized by the type of data analysis methods 
Table 1 The distribution of projects containing the acronym "STEM" from 2007 to 2019 across program options

\begin{tabular}{lll}
\hline Program option* & Number & Percentage \\
\hline Career and Technical Education & 1 & $1.9 \%$ \\
Center for Civic Education & 1 & $1.9 \%$ \\
Cognition and Student Learning & 3 & $20.4 \%$ \\
Early Learning Programs and Policies & 2 & $5.6 \%$ \\
Education Technology & 3 & $3.7 \%$ \\
Effective Teachers and Effective Teaching & 1 & $5.6 \%$ \\
English Learners & 1 & $1.9 \%$ \\
Low-Cost, Short-Duration Evaluation of Education Interventions & 1 & $1.9 \%$ \\
Postdoctoral Research Training Program in the Education Sciences & $1.9 \%$ \\
Postsecondary and Adult Education & 6 & $11.1 \%$ \\
Researcher-Practitioner Partnerships in Education Research & 1 & $1.9 \%$ \\
Science, Technology, Engineering, and Mathematics (STEM) Education & $\mathbf{2}$ & $\mathbf{3 . 7 \%}$ \\
Small Business Innovation Research & 17 & $31.5 \%$ \\
Small Business Innovation Research in Special Education & 2 & $3.7 \%$ \\
Special Topic: Career and Technical Education for Students with Disabilities & 1 & $1.9 \%$ \\
Unsolicited and Other Awards & 1 & $1.9 \%$ \\
Total & 54 & $100 \%$ \\
\hline
\end{tabular}

*all of these program options are under the category of "Education Research," except the two italicized program options (Small Business Innovation Research in Special Education, Special Topic: Career and Technical Education for Students with Disabilities) that are under the category of "Special Education Research." The bolded program option (Science, Technology, Engineering, and Mathematics (STEM) Education) is the designated STEM education program option

\section{Abbreviations}

ANOVA: Analysis of variance; DBER: Discipline-based education research; ED: Department of Education; HLM: Hierarchical linear modeling; IES: Institute of Education Sciences; IRT: Item response theory; NSF: National Science Foundation; Pre-12: Pre-school-grade 12; RFP: Requests-for-proposal; SEM: Structural equation modeling; STEM: Science, technology, engineering, and mathematics

\section{Authors' contributions}

YL conceptualized the study and drafted the manuscript. KW contributed with data collection, coding, analyses, and manuscript reviews. YX contributed to data collection, coding, and manuscript reviews. JEF and SBN contributed to manuscript improvement through manuscript reviews and revisions. All authors read and approved the final manuscript.

\section{Funding}

This review was supported by a grant from the National Science Foundation (DUE-1852942). Any opinions, findings, and conclusions or recommendations expressed in this material are those of the author(s) and do not necessarily reflect the views of the National Science Foundation.

\section{Availability of data and materials}

The data and materials used and analyzed for the review are publicly available at the IES website, White House website, and other government agency websites.

\section{Competing interests}

The authors declare that they have no competing interests.

\section{Author details}

${ }^{1}$ Texas A\&M University, College Station, TX 77843-4232, USA. ${ }^{2}$ Nicholls State University, Thibodaux, LA 70310, USA. ${ }^{3}$ Ohio State University, Columbus, OH 43210, USA.
Received: 18 March 2020 Accepted: 20 March 2020

Published online: 22 April 2020

\section{References}

Committee on STEM Education, National Science \& Technology Council, the White House (2018). Charting a course for success: America's strategy for STEM education. Washington, DC. https://www.whitehouse.gov/wp-content/ uploads/2018/12/STEM-Education-Strategic-Plan-2018.pdf Accessed on 18 Jan 2019.

English, L. D. (2016). STEM education K-12: perspectives on integration. International Journal of STEM Education, 3, 3 https://doi.org/10.1186/s4059 4016-0036-1.

Honey, M., Pearson, G., \& Schweingruber, A. (2014). STEM integration in K-12 education: status, prospects, and an agenda for research. Washington DC: National Academies Press.

Institute of Education Sciences (IES) (n.d.). About IES: connecting research, policy and practice. Retrieved from https://ies.ed.gov/aboutus/ Accessed on 2 Feb 2020.

Institute of Education Sciences (IES) \& National Science Foundation (NSF). (2013). Common guidelines for education research and development. Washington, DC: The authors. Retrieved from https://www.nsf.gov/pubs/2013/nsf13126/ nsf13126.pdf Accessed on 2 Feb 2020.

Lee, A. (2014). Students with disabilities choosing science technology engineering and math (STEM) majors in postsecondary institutions. Journal of Postsecondary Education and Disability, 27(3), 261-272.

$\mathrm{Li}, \mathrm{Y}$. (2014). International journal of STEM education - a platform to promote STEM education and research worldwide. International Journal of STEM Education, 1, 1 https://doi.org/10.1186/2196-7822-1-1.

Li, Y. (2018a). Journal for STEM Education Research - promoting the development of interdisciplinary research in STEM education. Journal for STEM Education Research, 1(1-2), 1-6 https://doi.org/10.1007/s41979-0180009-Z.

Li, Y. (2018b). Four years of development as a gathering place for international researchers and readers in STEM education. International Journal of STEM Education, 5, 54 https://doi.org/10.1186/s40594-018-0153-0.

$\mathrm{Li}, \mathrm{Y}$. (2019). Five years of development in pursuing excellence in quality and global impact to become the first journal in STEM education covered in SSCl. 
International Journal of STEM Education, 6, 42 https://doi.org/10.1186/s40594019-0198-8.

Li, Y., Froyd, J. E., \& Wang, K. (2019). Learning about research and readership development in STEM education: a systematic analysis of the journal's publications from 2014 to 2018. International Journal of STEM Education, 6, 19 https://doi.org/10.1186/s40594-019-0176-1.

Li, Y., \& Schoenfeld, A. H. (2019). Problematizing teaching and learning mathematics as 'given' in STEM education. International Journal of STEM Education, 6, 44 https://doi.org/10.1186/s40594-019-0197-9.

Li, Y., Wang, K., Xiao, Y., \& Froyd, J. E. (2020). Research and trends in STEM education: a systematic review of journal publications. International Journal of STEM Education, 7, 11 https://doi.org/10.1186/s40594-020-00207-6.

Margot, K. C., \& Kettler, T. (2019). Teachers' perception of STEM integration and education: a systematic literature review. International Journal of STEM Education, 6, 2 https://doi.org/10.1186/s40594-018-0151-2.

Minichiello, A., Hood, J. R., \& Harkness, D. S. (2018). Bring user experience design to bear on STEM education: a narrative literature review. Journal for STEM Education Research, 1(1-2), 7-33.

National Research Council. (2012). Discipline-based education research: understanding and improving learning in undergraduate science and engineering. Washington DC: National Academies Press.

Otten, M., Van den Heuvel-Panhuizen, M., \& Veldhuis, M. (2019). The balance model for teaching linear equations: a systematic literature review. International Journal of STEM Education, 6, 30 https://doi.org/10.1186/s40594019-0183-2.

Schreffler, J., Vasquez III, E., Chini, J., \& James, W. (2019). Universal design for learning in postsecondary STEM education for students with disabilities: a systematic literature review. International Journal of STEM Education, 6, 8 https://doi.org/10.1186/s40594-019-0161-8.

The White House (2009). President Obama launches "Educate to Innovate" campaign for excellence in science, technology, engineering \& math (Stem) education. Retrieved from https://obamawhitehouse.archives.gov/the-pressoffice/president-obama-launches-educate-innovate-campaign-excellencescience-technology-en Accessed on 2 Feb 2020.

The White House (2017). Presidential memorandum for the secretary of Education. Retrieved from https://www.whitehouse.gov/presidential-actions/ presidential-memorandum-secretary-education/ Accessed on 2 Feb 2020

The White House (2018). President Donald J. Trump is working to ensure all Americans have access to STEM education. Retrieved from https://www. whitehouse.gov/briefings-statements/president-donald-j-trump-is-working-toensure-all-americans-have-access-to-stem-education/ Accessed on 2 Feb 2020.

U.S. Department of Education (2018). U.S. Department of Education fulfills administration promise to invest \$200 million in STEM education. Retrieved from https:/www.ed.gov/news/press-releases/us-department-educationfulfills-administration-promise-invest-200-million-stem-education Accessed on 2 Feb 2020.

Wang, K., Li, Y., \& Xiao, Y. (2019). Exploring the status and development trends of STEM education research: the case of IES funded projects on STEM education in the U.S. 数学教育学报. Journal of Mathematics Education, 28(3), 53-61.

\section{Publisher's Note}

Springer Nature remains neutral with regard to jurisdictional claims in published maps and institutional affiliations.

\section{Submit your manuscript to a SpringerOpen ${ }^{\circ}$ journal and benefit from:}

- Convenient online submission

- Rigorous peer review

- Open access: articles freely available online

- High visibility within the field

- Retaining the copyright to your article

Submit your next manuscript at $\boldsymbol{\nabla}$ springeropen.com 